\title{
A Poliarquia Brasileira e a Reforma Política: Análise de uma Contribuição de Wanderley Guilherme dos Santos à Teoria Política*
}

\author{
Marcelo Sevaybricker Moreira \\ Professor-adjunto da Universidade Federal de Lavras (UFLA), Lavras, Minas Gerais, Brasil. \\ E-mail: marcelomoreira@dch.ufla.br
}

\begin{abstract}
obra de Wanderley Guilherme dos Santos, como a de alguns outros intelectuais de sua geração, carece ainda de um estudo mais sistemático a seu respeito. Como parece ser próprio do pensamento político brasileiro, subárea acadêmica das Ciências Sociais no país, estudos sobre os intelectuais mais recentes são a exceção, não a regra.
\end{abstract}

Tendo publicado diversos livros e artigos no círculo mais restrito da academia, mas também na imprensa sobre a política brasileira ao longo de mais de cinquenta anos, Santos pode ser considerado um dos "pais-fundadores" da Ciência Política no país que, no final dos anos 1960, contribuiu para a delimitação e a autonomização desse campo de estudos, através da incorporação e da criação de metodologias, de índices de pesquisa e de novas teorias para se pensar a política.

O presente artigo não tem a pretensão de recobrir toda a lacuna mencionada, simplesmente visa apresentar uma visão parcial de seu pensamento, abordando a sua obra através de um dos seus modos de presença na cena pública brasileira, isto é, as maneiras pelas quais esse

\footnotetext{
* Agradeço aos pareceristas anônimos de DADOS - Revista de Ciências Sociais pelos comentários, bem como a Juarez Rocha Guimarães pela orientação cuidadosa, nos últimos anos, no estudo da obra de Wanderley Guilherme dos Santos. Evidentemente, todos estão isentos de qualquer responsabilidade pelos possíveis equívocos do presente artigo.

DADOS - Revista de Ciências Sociais, Rio de Janeiro, vol. 57, no-2, 2014, pp. 293 a 323.
} 
conjunto de ideias e falas se fazem presentes nos discursos dos atores políticos e na intelectualidade de hoje.

A interpretação aqui esposada assevera que a sua obra se mantém presente, entre outras razões, quando se avalia a qualidade da democracia e, especialmente, quando essa avaliação é associada ao debate acerca da reforma política. Desde os anos 1990, Wanderley Guilherme tem se esforçado em salientar os aspectos positivos do atual sistema político brasileiro, não se opondo a todas as propostas de reforma política, mas àquelas que, em sua opinião, limitariam o potencial da democracia brasileira, sobretudo a adoção da cláusula de barreiras para os partidos, o voto em lista fechada e a substituição do sistema de representação proporcional pelo majoritário, isto é, justamente a terapêutica comumente recomendada por alguns estudiosos e defendida, com frequência, nos meios de comunicação do país. Muitos de seus textos têm como objetivo principal contestar as supostas vantagens de adotar essas propostas, constituindo-se em um interessante material de estudo do debate público brasileiro, como contraponto a certa hegemonia de valorização dessas medidas e de avaliação precipuamente negativa da democracia brasileira. Para Santos, essas propostas representam (ao contrário do que se afirma) um esforço das oligarquias tradicionais, temerosas frente ao processo de expansão cívica vivenciado no país desde a redemocratização, visando reduzir a competição pelos cargos de poder.

Além de ter um papel de destaque na cena pública brasileira no que tange à avaliação da qualidade de nossa democracia (e, por conseguinte, no debate sobre a reforma política), Santos formulou uma nova e importante narrativa histórica acerca da formação política do país. Nela, a democracia brasileira emerge dos conflitos internos à oligarquia do passado em um processo que não é teleológico, nem encarcerável, e, portanto, sujeito a retrocessos. O caso do Brasil é, na visão do autor, particularmente mais complexo do que o das democracias mais "antigas", dado que a formação de sua democracia ocorreu em um contexto institucional adverso, na medida em que nem mesmo a integração do território nacional havia sido plenamente realizada e na qual se tinha que lidar, simultaneamente, com pressões por ampliação da participação política e também por distribuição da riqueza. A democracia, assegura ele, como fenômeno político mundial é uma invenção de efetividade muito recente, uma vez que é irreal falar nela antes da consolidação do sufrágio universal. Nesse sentido, sua dinâmica é ainda pou- 
co compreendida, o que deveria sugerir mais prudência ao tentar modificar as suas regras de competição política, sobretudo porque os efeitos das inovações tendem a contrariar as expectativas de seus propugnadores.

Como horizonte normativo da consolidação da democracia no Brasil, o autor reafirma a necessidade de manter (e, se possível, aumentar) os atuais níveis de competição e de participação política (bastante satisfatórios quando comparados com os de outros países) e de realizar, ao mesmo tempo, a constitucionalização de todo o território brasileiro. É essa última dimensão - a dos direitos civis e não a dos direitos políticos - que ainda carece de efetiva universalização no país. Por conta disso, o autor assevera que subsiste no Brasil um "híbrido institucional", caracterizado por excessiva legislação poliárquica a contrastar com uma sociabilidade belicosa e não cívica.

Essa interpretação do Brasil criada por Wanderley Guilherme dos Santos expressa, por seu turno, uma teoria política bastante particular, formada em evidente contato com os conceitos e métodos forjados pela moderna Ciência Política, especialmente na sua matriz estadunidense, da qual Santos foi um dos primeiros a se apropriar de modo sistemático no país. No entanto, longe de constituir uma mera imitação de ideias criadas alhures, trata-se de uma reflexão crítica e criativa, como é o caso da incorporação por parte de Santos da conhecida teoria da poliarquia, formulada por Robert Dahl. É precisamente mediante essa teoria que Wanderley Guilherme organiza sua interpretação do Brasil e, ao mesmo tempo, se arma contra aqueles que querem reverter o processo de democratização do país. Considera-se que, para além de apenas analisar a realidade brasileira à luz dessa teoria, Santos foi capaz de dar uma contribuição importante para a teoria democrática como um todo, revelando possibilidades não antevistas pela obra dahlsiana.

É curioso constatar que a obra de Santos também foi formada mediante a apropriação de certos intelectuais da tradição nacional, como José de Alencar e Oliveira Vianna, entre outros, retomados por Santos desde as suas primeiras publicações, no final dos anos 1960, e que constituíram estudos pioneiros no que hoje se convencionou chamar de pensamento político brasileiro. Assim, Santos é igualmente um intelectual profundamente interessado no que foi denominado, muitas vezes de modo pejorativo, de tradição "ensaísta" brasileira, revelando que nem sempre o desejo de se fundar uma nova ciência da política no país esteve 
associado a um esforço de romper com o nosso passado intelectual ${ }^{1}$. Mais do que isso, esses textos de Santos continuam a servir de referência obrigatória (ainda que não necessariamente suficiente) para aqueles que se dedicam ao estudo do pensamento do país, como é o caso de sua interpretação acerca da obra de Vianna. Há, enfim, afinidades interessantes a serem exploradas entre o pensamento desses autores e do próprio Wanderley Guilherme, como a crítica contra certa tendência à imitação, tida como típica dos intelectuais brasileiros, que descurando das particularidades próprias do contexto nacional, acabam por incorporar diagnósticos e prognósticos feitos por especialistas dos países centrais.

É nesse sentido que Santos intervém polemicamente no debate público não apenas contra os que, receosos da perda de privilégios, se armam contra ela, pretendendo restringir a competição política, mas também contra aqueles que, baseados numa concepção "idealizada" de governo - e organizados teoricamente sob as denominações da "democracia participativa" e do "neorrepublicanismo" -, identificam atualmente um déficit democrático entre nós.

A argumentação deste artigo compreenderá cinco momentos distintos. No primeiro, far-se-á uma breve exposição de algumas ideias correntes no debate que se trava no país desde a redemocratização acerca da reforma política. Sem exaurir esse debate, o trabalho se volta centralmente para textos publicados por Bolívar Lamounier, outro intelectual da primeira geração de politólogos brasileiros, e tomado aqui como um dos expoentes dos que defendem uma ampla transformação do sistema político brasileiro. Em seguida, passa-se à interpretação de Wanderley Guilherme sobre a criação e consolidação da democracia brasileira, formulada a partir da teoria poliárquica. No terceiro momento, avalia-se um tema fundamental em sua interpretação do Brasil, qual seja, a construção do Estado nacional e da ordem burguesa, e a contribuição e limites da política varguista na realização dessas metas. A questão da ordem burguesa é encarada por ele como um patamar necessário para o bom funcionamento da poliarquia, requisito ainda não satisfeito plenamente no Brasil. Com frequência, as propostas de reforma política são justificadas a fim de negar a influência da era Vargas, o que justifica essa breve digressão no argumento. Em um quarto momento, retoma-se a discussão sobre o conceito de poliarquia, a fim de considerar as críticas de Wanderley Guilherme dos Santos a essa teoria e expor sua interpretação da reoligarquização da democracia brasilei- 
ra. Na quinta seção, discute-se a avalição de Santos acerca de algumas das principais propostas de reforma política em pauta hoje e, por fim, pondera-se sobre a contribuição desse intelectual brasileiro em relação ao debate da reforma política, levando em consideração a disputa normativa em torno da definição do que deve ser a democracia no tempo presente. A despeito de se concordar ou não com os argumentos desse autor, fato é que sua obra foi fundamental na conformação da moderna Ciência Política brasileira e que criou uma interpretação original e relevante sobre o país.

\section{O DEBATE SOBRE A REFORMA POLÍTICA}

Nas últimas três décadas, o debate sobre as instituições políticas da democracia brasileira tem se intensificado bastante. Inúmeras propostas de reforma política têm sido apresentadas no Congresso Nacional, algumas vezes apoiadas por parte da mídia, sendo que algumas delas podem vir a ser aprovadas em breve. Adoção do parlamentarismo, do voto facultativo, do financiamento exclusivamente público das campanhas eleitorais, da cláusula de barreira para os partidos "nanicos", da proibição das coligações partidárias para os cargos de representação proporcional, da substituição desse sistema de representação pela representação majoritária, implementação do voto em lista fechada, são, em suma, as principais modificações sugeridas desde a redemocratização do país. Em geral, defende-se que a adoção de tais medidas serviria para corrigir as deficiências herdadas de nossa política oligárquica, populista, corrupta, centralizadora, fragmentada, instável, distorcida do ponto de vista da representação etc.

Bolívar Lamounier elenca algumas das razões mais comuns favoráveis à reforma política. O Brasil, logo após ter-se redemocratizado, estaria vivendo uma crise por causa do esgotamento de seu sistema político. Segundo esse autor, esse sistema, que teve suas bases estabelecidas por Getúlio Vargas a partir dos anos 1930, caracteriza-se por um tripé "extremamente problemático" formado por "arranjos excessivamente consociativos na esfera eleitoral-partidária, corporativismo na área sindical e presidencialismo plebiscitário" (Lamounier, 1992:4). O consociativismo seria decorrente da representação proporcional, que faz com que o Executivo federal tenha que negociar com um número muito elevado e diversificado de partidos na Câmara dos Deputados, produzindo um sistema político-partidário fragmentado, com dificuldade de estabelecer uma maioria estável. Aliados a isso, haveriam ain- 
da os agravantes do voto em lista aberta e da facilidade da formação de partidos. Equacionando-se esses três elementos, o resultado inevitável seria a ingovernabilidade. O segundo elemento é o corporativismo sindical que consiste em "remover os conflitos capital/trabalho da arena político-partidária e confiná-los a um subsistema específico, no qual preponderam enfoques judiciários e administrativos" (Lamounier, 1992:47). O processo de negociação de conflito entre trabalhadores e empresários passara a ser tutelado pelo Estado que, por meio do monopólio da representação sindical e do imposto sindical obrigatório, conseguiu controlar os trabalhadores com vistas a promover a ordem social. Mesmo sendo duramente criticado como "fascista", o corporativismo teria sido mantido, em linhas gerais, na política brasileira. $\mathrm{O}$ último elemento caduco legado pelo getulismo seria a predisposição do país à emergência de líderes políticos que, ao assumirem o poder, dispensam e negligenciam as instituições políticas básicas de uma democracia moderna.

Dado o diagnóstico pessimista, Lamounier passa então a descrever como reformar nosso arcabouço institucional. Negando a razoabilidade da aplicação imediata de um sistema bipartidário e do voto distrital puro, o autor defende um conjunto de medidas que inclui parlamentarismo, voto distrital misto e cláusula de barreiras, isso frente à iminência (à época) da realização de um plebiscito popular sobre a forma de governo ${ }^{2}$.

Não é o caso, todavia, de assumir que esse autor resuma todas as razões favoráveis à reforma política no Brasil, nem tampouco que a defesa de uma dessas medidas implique o assentimento com as demais. No entanto, Lamounier pode ser considerado um intelectual representativo de uma corrente importante na Ciência Política brasileira (e com notória visibilidade nos meios de comunicação) que ressalta a ineficiência, a instabilidade e o anacronismo de alguns aspectos do sistema político brasileiro e que defende a necessidade de uma ampla reforma política no País.

Apesar de tentar justificar seus argumentos mediante a opinião majoritária de "especialistas" da política, a posição de Lamounier está longe de ser consensual. Mesmo restrita à Ciência Política, área acadêmica que concentra boa parte do debate especializado sobre a reforma política, cada uma dessas propostas é bastante controversa. Há, inclusive, uma vertente frontalmente contrária à representada por Lamounier e 
que se constitui de certa "apologia" do regime democrático brasileiro em seu estado atual; ainda que não seja considerado como isento de problemas, ele é caracterizado, sobretudo, pelos seus avanços em incorporar boa parte dos indivíduos do país à vida democrática, tornando a disputa pelos cargos de poder cada vez mais competitiva. Nessa vertente, destaca-se, sobremaneira, a obra de Wanderley Guilherme dos Santos.

\section{POLIARQUIA: UM MODELO TEÓRICO PARA SE PENSAR O BRASIL}

A obra de Santos é, decerto, muito extensa para ser avaliada metodicamente no espaço de um artigo ${ }^{3}$. Ao se concentrar na teoria da poliarquia, a presente pesquisa está pressupondo que ela, embora não seja a única referência importante, é certamente aquela que melhor caracteriza sua obra, pelo menos no que se refere ao conceito de democracia de que esse autor se vale (Santos, 1993:2).

Como se sabe, o conceito de poliarquia é utilizado por Dahl para descrever a concepção de democracia que concilia a maximização das metas da soberania popular e da igualdade política com as condições políticas da modernidade. Ainda que imperfeita, a poliarquia é o regime político que mais se aproxima do ideal democrático.

No célebre livro Poliarquia, Dahl assevera que esse tipo de regime político é definido por ser um governo responsivo às preferências de seus cidadãos. Para que isso ocorra, é forçoso que oito garantias sejam oferecidas ${ }^{4}$, o que pode também ser traduzido como a consolidação de dois eixos da dinâmica política: a liberalização (contestação pública) e a participação. Regimes poliárquicos são regimes amplamente (ainda que não totalmente) liberalizados e participativos.

Dahl argumenta que a poliarquia é um tipo de regime que baseia sua existência numa confluência de condições sociais prévias, mais do que em freios constitucionais. Essa confluência compõe uma sociedade "moderna, dinâmica e plural" (MDP): 1) moderna (urbana, industrializada, com elevados índices de riqueza, educação etc.); 2) dinâmica (crescimento econômico e um aumento contínuo no padrão de vida dos indivíduos); e 3) plural, pois há uma dispersão entre os atores sociais dos recursos politicamente relevantes. Embora não seja condição suficiente, uma sociedade MDP é um fator decisivo para o sucesso da poliarquia. 
Esse tipo de sociedade acaba por constituir o que Dahl denomina um sistema de segurança mútua, no qual os competidores pelos cargos de poder consideram que é mais razoável tolerar a derrota eleitoral do que romper com as regras da competição política. O autor considera algumas variáveis que contribuem para a criação das garantias mútuas, dando um destaque particular para a sequência histórica. No que diz respeito a esse fator, é mais provável que surja uma poliarquia estável quando a liberalização precede a ampliação da participação, pois a prática competitiva se restringe inicialmente a poucos grupos, mais coesos entre si, só depois sendo estendida a outros indivíduos.

Outros caminhos da democratização seriam mais arriscados, exatamente por não terem consolidado o sistema de segurança mútua e por ser improvável que isso ocorra quando já há um número elevado e heterogêneo de líderes representando camadas sociais diversas. Entretanto, essa sequência histórica estava vedada aos países que se democratizavam no século $X X$, visto que a pressão por ampliação da participação já era muito forte a essa época. O grande desafio, então, é a construção desse sistema de garantias mútuas sob a vigência de participação ampliada.

Ora, o Brasil é justamente um caso de democratização tardia. Levando em consideração esse prognóstico pouco otimista, Wanderley Guilherme dos Santos adotou a teoria da poliarquia para pensar a realidade brasileira, formulando uma nova interpretação sobre a democracia brasileira.

No livro Razões da Desordem, Wanderley Guilherme procura analisar, em comparação com a experiência inglesa (tomada por Dahl como modelo), como se formou a ordem brasileira, enfatizando duas questões comuns às sociedades modernas: o "alargamento da participação e da institucionalização da competição política" e a "integração institucional", sendo que somente o primeiro processo foi analisado com centralidade por Dahl (Santos, 1993:9).

No fim do século XIX, a Inglaterra terminou o seu primeiro surto de industrialização e preparava-se para a adoção do livre-comércio e a expansão imperial de sua economia, que auxiliaria o país a passar de forma menos instável pelos séculos XIX e XX. Esse processo foi fundamental, pois permitiu a integração institucional da Nação, garantindo também um mercado nacional, um sistema de comunicação e transporte ampliados etc. Outro fator de estabilização, afirma Santos, con- 
sistiu no fato de que o País contou com um sistema político aceito por boa parte das lideranças operárias. Restrito às tradicionais oligarquias do país, o regime de competição política pôde se institucionalizar, criando as garantias mútuas. Doravante, foi-se ampliando aos poucos, mediante a extinção de barreiras à participação. Até aqui, nada de novo: Santos repete a descrição de Dahl na qual a liberalização precede a ampliação da participação, gerando, por suposto, maior estabilidade política. Santos observa, contudo, que houve um terceiro momento desse processo, não avaliado por Dahl. Somente depois de liberalizado e já inclusivo, com as identidades políticas dos atores já formadas por meio dos partidos, é que o sistema político inglês começa a solucionar a questão social.

Comparado à Inglaterra, o caso brasileiro é bem diverso. Sendo uma colônia, o mesmo processo de acumulação de riquezas via expansão mundial do comércio, que favorecera a integração nacional inglesa, gerou segmentação e desigualdade entre as regiões brasileiras. Como outros países latino-americanos, aqui vivia-se "extemporaneamente" o problema liberal básico: o caráter errático do país impedia a formação de uma ordem burguesa ${ }^{5}$. O pacto oligárquico, ainda que instável, mantinha sob seu comando o Estado brasileiro, que pouco podia contra os "leviatãs estaduais". O verdadeiro divisor de águas com esse padrão foi a Revolução de 1930, pois, daí em diante, o Estado brasileiro, em condições ainda de reduzidas institucionalização e participação política, garantiria precocemente os direitos sociais, sendo utilizados a fim de garantir a inclusão à cidadania, ainda que de forma tutelada.

A partir da contraposição resumida entre as histórias políticas da Inglaterra e do Brasil, Santos conclui que seria possível pensar em outras possibilidades do processo de democratização, se o problema distributivo fosse levado em consideração. O caso brasileiro seria exemplar (mas não único), no qual a legislação social foi empregada em momentos de crise e de reduzidas liberalização e participação política, como se deu no Estado Novo e durante a ditadura militar de 1964.

Tendo em vista essa outra sequência de democratização, indaga-se Wanderley Guilherme: deve-se considerar o Brasil no fim do século XX uma poliarquia? Para responder a essa questão, ele passa à análise das características sociopolíticas típicas de uma poliarquia. A primeira delas é a acumulação material: o Brasil não apenas cumpriu, no intervalo entre 1965 e 1980, o requisito da acumulação, com uma média de cresci- 
mento do PIB de 8,8\% (Santos, 1993:81), como a sua estrutura econômica tornou-se acentuadamente diversificada. Verificou-se, concomitantemente, intensa urbanização e crescimento das associações civis, quebrando o monopólio organizacional corporativista estabelecido nos anos 1930. Pode-se, então, dizer que a sociedade brasileira no final do século XX é uma sociedade moderna, dinâmica e plural (MDP), ainda que não igualitária. Outra característica é a expansão do eleitorado: ele teve uma média de crescimento de 31,2\% entre 1945 e 1986, o que se deu concomitantemente ao aumento da competitividade. "De 1950-1966 e, depois, a partir de 1974, o sistema partidário brasileiro foi, e é, competitivo" (ibidem:88). O último traço típico das poliarquias, a correlação entre participação e renda e educação aplica-se também à sociedade brasileira. Levando em consideração esse cenário, o autor indaga:

Ao que parece, e por todas as evidências, os requisitos de um sistema poliárquico foram atendidos apropriadamente pela sociedade brasileira (...). [Tudo isso] devia manifestar adequada capacidade de aprendizado diante de crises, reduzida taxa de desperdício e maior velocidade de recuperação após períodos de dificuldade. Por que tal não acontece com a poliarquia brasileira? (ibidem:89).

A resposta de Santos a essa pergunta exige avaliar, mais detidamente, outro elemento fundamental de seu pensamento: a formação da ordem burguesa no Brasil.

\section{A ORDEM BURGUESA E A ERA VARGAS}

O caso brasileiro sugere uma via complexa de democratização, na qual as identidades políticas são formadas sem a mediação dos partidos e antes da constituição da ordem política liberal, de modo que os atores envolvidos no conflito distributivo procuram vocalizar suas demandas não por meio da participação e da competição partidária, mas através da influência direta com parte da burocracia estatal, que passa a arbitrar essa disputa. Essa via produz, por seu turno, três consequências perversas. Em primeiro lugar, a submissão do operariado em relação à burocracia estatal. Em segundo, a irrelevância dos partidos políticos, instituições fundamentais nas poliarquias ${ }^{6}$. Esse formato institucional, o "corporativismo subdesenvolvido", no qual o conflito social está dissociado do processo político-partidário, dificulta a criação do sistema de segurança mútua, uma vez que às demandas da população foi 
dada uma outra solução. A terceira consequência é a própria utilização das políticas sociais a fim de compensar a participação limitada e a pouca competitividade política. Se, no caso inglês, os direitos sociais contribuíram para uma maior integração política, no Brasil significaram mais um obstáculo à institucionalização política.

Contra os que diagnosticavam uma crise de governabilidade nos anos 1990, como Lamounier, o autor apresenta uma outra explicação para a dificuldade governativa brasileira. Para ele, o principal dilema atual da ordem brasileira consiste num "híbrido institucional" aqui instaurado: por um lado, "uma morfologia poliárquica, excessivamente legisladora e regulatória" e, por outro, um "hobbesianismo social préparticipatório e estatofóbico" (Santos, 1993:79). Como em um estado de natureza, a fragilidade das normas de convivência produz uma desconfiança generalizada, prevalecendo, então, os códigos privados de comportamento. O resultado ulterior desse estado de natureza é, na visão de Santos, uma "cultura cívica predatória", com um padrão de interação social de soma zero quando bem-sucedida, ou de soma negativa quando fracassa.

Curioso pensar que a tese do híbrido institucional retoma o tema caro aos intelectuais da década de 1920-30 dos "dois Brasis" e a percepção dicotômica da realidade nacional, identificada pelo próprio autor (Santos, 1970). Justo dizer que não se trata dos "dois Brasis", tal como em Euclides da Cunha (um rural e atrasado e outro, urbano e modernizado), mas "dois Brasis" porque há um hiato entre a ordem institucional (poliárquica) e a ordem social (hobbesiana).

As funções básicas de uma poliarquia eficaz, a saber, provisão de segurança, proteção, previsibilidade e administração da justiça, não chegam a alcançar extensão considerável do universo social brasileiro. Não se trata aqui, porém, e isto é de extraordinária importância e extrema gravidade, de uma segmentação geográfica (...), nem um hiato explicável pela estratificação das classes ou pela distribuição de renda. (...). Os dois Brasis apontam para uma dicotomia institucional, um híbrido, do qual participam ricos e pobres, profissionais liberais, líderes sindicais e empresários, em todas as regiões do país. (Santos, 1993:100-101; ênfases do autor)

O descrédito com a eficácia governamental - expresso tanto pelo indivíduo que, violentado, não procura o auxílio da polícia, quanto por aquele que dispensa o recurso do voto como mecanismo de participa- 
ção - é visto como decisivo no insucesso de algumas políticas públicas. Santos argumenta que, se os "especialistas" da política revelam a impressão difusa de um mal funcionamento da democracia, isto se deve menos a uma deficiência das instituições políticas e mais a uma carência de direitos constitucionais elementares. Para Santos, há uma péssima distribuição desses direitos no país, mais grave do que a sempre lembrada desigualdade social. Sem uma cultura cívica capaz de fundamentar as instituições poliárquicas existentes, o autor vê com descrença qualquer reforma institucional e explica ironicamente que "não se trata de pessimismo, mas neste momento, não há cultura cívica no país, apenas natureza. Exuberante, é claro, como convém a um país tropical" (Santos, 1993:135).

Para ele, é imprescindível expandir o Estado Mínimo a fim de garantir eficácia à ação estatal. É por isso que Santos polemizava, à época, contra a política adotada pelo governo federal de sucatear o Estado brasileiro (constituído incialmente por Vargas e já bastante frágil) sob a justificativa de ele ser corrupto, clientelista etc. Embora os críticos tenham razão em apontar alguns aspectos negativos da tradição varguista, eles não compreendem, argumenta Santos, que essas políticas se constituíram como uma reação viável diante de circunstâncias tão adversas. Se até 1930 reinava a total ausência de leis de proteção social, a partir daí inaugura-se uma nova ordem na política brasileira, a cidadania regula$d a$ :

Por cidadania regulada entendo o conceito de cidadania cujas raízes encontram-se, não em um código de valores políticos, mas em um sistema de estratificação ocupacional, e que ademais, tal sistema de estratificação ocupacional é definido por norma legal. Em outras palavras, são cidadãos todos aqueles membros da comunidade que se encontram localizados em qualquer uma das ocupações reconhecidas e definidas em lei. (Santos, 1979:75; ênfases do autor)

Se isso significou um avanço em comparação com a ausência institucional anterior (com a criação de vários direitos para os trabalhadores que coibiam os excessos do processo de produção), representou, ao mesmo tempo, a possibilidade de o Estado "domesticar" o operariado. Apesar de ter gerado a "cidadania regulada", Santos não endossa o diagnóstico totalmente negativo a respeito do varguismo. Em primeiro lugar, por ele ter sido o responsável por construir inicialmente o Estado nacional. Em segundo, porque ele resolveu quase simultaneamente outros dois dilemas fundamentais da ordem social moderna, a 
redistribuição das riquezas e a participação política ampliada, dilemas, em geral, solucionados em momentos distintos e ao longo de séculos nas democracias europeias. A maior dificuldade em solucionar concomitantemente os problemas da integração nacional, da participação política e da redistribuição é que a criação de uma ordem liberal promoveria a continuação do domínio exclusivo dos oligarcas, como ocorria na Primeira República. Assim, a via da modernização, iniciando-se pela integração nacional, seguida da ampliação da participação política e, por fim, da redistribuição (sequência adotada pelos países desenvolvidos) não era viável para o Brasil.

É no tratamento a esse tópico que o democrata Wanderley Guilherme dos Santos dá destaque à obra do saquarema Oliveira Vianna, na sua visão, um "autoritário instrumental" (Santos, 1978), que teria sido capaz de perceber que a constituição de uma ordem liberal no Brasil exigia, paradoxalmente, a utilização de meios não liberais. Evitando o debate sobre a adequação dessa interpretação, cumpre anotar que, para ambos, Vianna e Santos, o governo brasileiro necessitava, no contexto da Primeira República, recorrer ao autoritarismo a fim de romper com a sociedade oligárquica.

Conforme a interpretação formulada por Santos sobre a política brasileira, com a Era Vargas, se inicia um processo de decadência das oligarquias tradicionais, como decorrência da ação do Estado. Mesmo considerando as heranças negativas do varguismo na política nacional, como o corporativismo subdesenvolvido, a cidadania regulada e o autoritarismo, Wanderley Guilherme conclui, portanto, que essa tradição criou as condições mínimas para o surgimento da poliarquia brasileira, institucionalizando gradualmente a competição política e ampliando a participação política de setores antes marginalizados ${ }^{7}$. Quando o número de competidores é restrito e o eleitorado, em sua maioria, vive na zona rural, esse se encontra basicamente dependente dos clãs familiares que competem pelo poder através das eleições. $\mathrm{Na}$ medida em que ele se expande, tornando o eleitor um anônimo e preponderantemente da cidade, essa dinâmica acaba.

Políticos cortejam os eleitores porque os temem e quanto mais intensa for a competição, maior é a insegurança dos candidatos sobre o veredicto público. Com o crescimento do eleitorado e do número de eleitores, além da percepção de que a maioria absoluta dos eleitores revela plena autonomia na escolha de seus candidatos (...), os resultados eleitorais tendem a se tornar cada vez mais imprevisíveis. (Santos, 2007a:223) 
A transformação da política nacional, costumeiramente menosprezada pelos analistas políticos que se limitam a caracterizar Vargas como ditador e/ou populista, trouxe consequências novas e radicais para a construção da democracia brasileira. Todavia, tal processo contém potencialmente formas de regresso ao nosso passado oligárquico. Essas formas estariam sendo defendidas sob as propostas da reforma política, verdadeiras "máscaras institucionais do liberalismo oligárquico" (Santos, 1994).

\section{PROCEDIMENTOS DECISÓRIOS E PARTICIPAÇÃO POLÍTICA}

Em "Poliarquia em 3D", Wanderley Guilherme retoma a teoria poliárquica a fim de destacar sua importância na interpretação da realidade política, mas também mais algumas de suas insuficiências. A crítica de Santos não redunda em uma ruptura com a teoria poliárquica, mas visa a primorá-la, sobretudo, no que concerne ao modo de se conceber o eixo da participação política. Além disso, a apropriação crítica de Santos da teoria de Dahl revela algumas afinidades e também diferenças entre esses autores.

Wanderley Guilherme esclarece no referido artigo que sua abordagem da democracia é meramente institucional. Uma vez que mesmo regimes democráticos podem originar decisões antidemocráticas, isto é, não atendendo à maioria dos interesses, não se deve definir democracia em função de seus resultados, mas sim baseando-se nas instituições adotadas para a consecução dos resultados. Dahl, por seu turno, recusa a distinção entre democracia substantiva e democracia procedimental, afirmando que todo procedimento é imbuído de valores; pressupõe, portanto, certos resultados, do mesmo modo que todo resultado exige um certo procedimento para ser obtido (Dahl, 1989). Além disso, Dahl assevera que existem três critérios que servem para determinar quando o método democrático é melhor do que um não democrático: 1) quando o processo decisório pode garantir que a decisão corresponda à própria escolha do indivíduo envolvido (critério da escolha pessoal); 2) quando o processo democrático pode assegurar que decisões informadas por um especialista competente são piores do que as tomadas a partir de procedimentos democráticos (critério da competência); 3) quando, apesar de ser menos perfeita que os outros procedimentos, a autoridade democrática poupa ao indivíduo tempo, energia e empenho (critério da economia). 
A grande dificuldade, como comenta Santos, é que Dahl aceita que, desde que respeitados esses três critérios, em casos de dissenso da maioria - principalmente, com grupos dotados de preferências intensas e díspares -, é legítima a adoção do princípio de autoridade não democrática. No entanto, é exatamente esse princípio que é definido, no livro Poliarquia, como ilegítimo em contextos democráticos. Como resolver esse impasse? Dahl não apresenta uma resposta concludente para a questão, ao passo que a solução de Santos consiste, como se viu, em esposar uma concepção exclusivamente procedimental dos regimes políticos.

Essa questão é relevante, argumenta o autor brasileiro, porque revela um dilema concreto das democracias contemporâneas: o da representatividade da representação. De acordo com Wanderley Guilherme, quanto mais complexas as sociedades e quanto maior o eleitorado, maior a probabilidade, por um lado, de que o eleitor dependa de uma representação mais específica para seus interesses e, por outro, de que o candidato ao mandato tenha que, paradoxalmente, representar um número maior de interesses diversos. Sendo assim, o autor se interroga: deve-se aceitar o princípio de autoridade não democrática, quando a regra de decisão da maioria parecer plenamente arbitrária? Como a representatividade da representação é inversamente proporcional ao número de representados, é razoável supor, mesmo no caso de poliarquias, que "o número de interesses desfavoravelmente afetados por decisões majoritárias é potencialmente superior ao número de interesses atendidos (Santos, 1998a:214). O que está em jogo, portanto, é que, mesmo atendendo a todos os requisitos básicos da poliarquia, os cidadãos podem se sentir efetivamente não representados. Ao modo de Robert Michels, Santos elabora esse dilema como "lei de ferro da insatisfação poliárquica": "Quanto mais heterogênea a sociedade e homogênea a classe política, maior o paradoxal hiato entre a adesão à mecânica da democracia e o repúdio à sua operação poliárquica; ou quem diz democracia, diz insatisfação democrática" (Santos, 1998a:217, ênfases do autor).

Destarte, conclui Santos, não se pode definir democracia em função de resultados, sem correr o risco de se deparar com resultados antidemocráticos. Ele apresenta, então, definições minimalistas de poliarquia, oligarquia e autocracia. A poliarquia, diz ele, é o sistema político que combina ampla competição eleitoral, com regras públicas e regulares, e sem o uso de violência por parte dos competidores (primeira condição), com a participação política ampliada na competição eleitoral (se- 
gunda condição). Sendo assim, pode-se dizer que as oligarquias caracterizam-se por satisfazer a primeira (liberalização), mas não a segunda condição (participação), já que o jogo político está restrito a poucos. A autocracia, por seu turno, distingue-se das duas primeiras formas de governo por não satisfazer nenhuma das duas condições, não podendo ser chamada de sistema representativo.

A fim de definir mais formalmente os sistemas representativos, o autor afirma que esses sistemas combinam quatro direitos fundamentais: 1) direito de expressão; 2) direito de organização, inclusive para competir pelos cargos representativos; 3 ) direito de votar; 4) direito de ser votado. Todo regime que suprimir qualquer um dos quatro direitos deixa, ipso facto, de ser representativo. O que distingue os dois tipos existentes de sistemas representativos é que, sendo escassa a competição no caso das oligarquias, torna-se mais ou menos previsível o seu resultado, ao passo que nas poliarquias ele é, no limite, aleatório.

Santos assevera que a teoria democrática não só desconsidera essa familiaridade entre esses dois sistemas políticos, como também costuma dar um tratamento ambíguo à oligarquia, na medida em que a classifica como próxima da autocracia, quando quer criticá-la, e associa-a à democracia, quando quer elogiá-la. Incorrendo nesse equívoco, os analistas fecharam os olhos para o fato de que várias sociedades do passado, tidas como democráticas, não passavam, a rigor, de oligarquias.

Os estudos mega-históricos de que tenho notícia adotam a dualidade autocracia/democracia, desconhecendo a possibilidade de a dicotomia fundamental ser sistemas não-representativos/sistemas representativos e, consequentemente, da mesma maneira que existem diversas formas de autoritarismo, a democracia ser, também, apenas uma das trajetórias dos sistemas representativos. (Santos, 1998a:208, ênfase do autor)

É importante frisar que essas oligarquias do passado demonstraram ser altamente estáveis, o que só não foi percebido porque elas eram identificadas como democracias e se associava, equivocadamente, estabilidade apenas a regimes democráticos. Esses regimes, inicialmente oligárquicos, foram capazes de constituir um sistema de segurança mútua e, só no desenrolar do século XX, transformaram-se em poliarquias, sem a ocorrência de qualquer violência institucional. Desta feita, a institucionalização das regras de competição política, nos termos 
de Dahl, que tem como princípio o sistema de garantias mútuas, é um fator de estabilidade de qualquer sistema representativo, poliárquico ou oligárquico. Discordando de Dahl, Santos sugere que a estabilidade própria às poliarquias deve consistir em outro fator, não apenas nas garantias mútuas.

Outro erro comum consiste em supor que a passagem de regimes não democráticos (oligarquias ou autocracias) para as democracias (e vice-versa), implica sempre violência física ou institucional. Se oligarquia e democracia são apenas variações do sistema representativo, é possível transitar entre um e outro sem qualquer tipo de violência. A transição para as democracias costumeiramente foi pensada em relação ao autoritarismo, descartando a possibilidade de que essas se convertam em sistemas oligárquicos. Isso significa que, dependendo do número de competidores do jogo político, é possível não ser ainda democrático sem ser necessariamente autoritário. "A redução dos sistemas representativos à linearidade democrática, limitando-se as variações principalmente às formas de governo e aos sistemas eleitorais, não corresponde à complexidade crescente das organizações políticas nacionais" (Santos, 1998a:209).

Como se sabe, Dahl enumera oito condições necessárias às poliarquias, sendo que a quarta condição diz respeito exatamente à possibilidade de concorrer pelos cargos em disputa ("elegibilidade"). O próprio Wanderley Guilherme reconhece isso (Santos, 1998a:220), mas considera que essa dimensão é tratada de modo ambíguo pelo autor, ora significando elegibilidade no sentido fraco, ora no sentido forte.

Santos propõe, então, o acréscimo de um terceiro eixo da democratização, chamado de controle (direito de ser votado), distinguindo-o mais claramente da participação (direito de votar). A distinção justifica-se porque as regras de qualificação do eleitor não são idênticas às do elegível. Além dessa razão inicial, é preciso estabelecer essa diferenciação para observar que, do mesmo modo que um país pode avançar muito na institucionalização e pouco na participação, pode-se também avançar muito na participação e pouco no controle. Uma última justificativa para a introdução do terceiro eixo é que, uma vez consolidado o sufrágio universal, por meio da alteração legal das regras de competição política, é possível restringir a representatividade alterando não o eixo da participação, mas o do controle. 
Santos defende, então, que os sistemas políticos representativos sejam compreendidos como uma combinação sempre variada dos três eixos: institucionalização, participação e controle, eixos que podem progredir ou regredir independentemente uns dos outros. Em resumo, embora seja o melhor modelo para se analisarem as democracias de hoje, a teoria poliárquica trata a competição política de modo simplificado. Competição há não apenas entre candidatos ou entre partidos, mas também segundo outras possibilidades, tornando mais complexos os caminhos que levam de um regime fechado a uma poliarquia (e vice-versa): “Aqui entende-se que a competição política pode estar referida a quatro processos distintos: competição entre partidos, competição entre candidatos, competição intrapartidária entre os candidatos e competição entre os candidatos independentemente de filiação partidária" (Santos, 2007b:40-41).

As distinções propostas por Santos são, portanto, entre, de um lado, a institucionalização da competição política e a definição de quem está qualificado para ser candidato-representante, e, de outro, o candidato a um cargo eletivo e o mero cidadão-eleitor. A manipulação oligárquica dos elegíveis também pode ocorrer de maneiras variadas: limite de idade, exigência de vinculação partidária, tempo de residência, restrição a partidos pequenos, proibição de candidaturas avulsas, designação de candidatos por listas fechadas etc. Assim, enquanto a condição de eleitor dificilmente pode ser restringida num regime democrático na atualidade (e, se o for, somente mediante violência institucional), a condição de elegível pode ser alterada dentro das regras do jogo democrático.

Para o autor, essa dinâmica combinatória entre os três eixos, envolvendo processos não encarceráveis, é crucial para entender todas as alternativas em jogo nos processos políticos, visto que, em sua opinião, a maior parte dos conflitos da atualidade ocorre tendo como foco o eixo do controle e não o da participação. Dada a consolidação do sufrágio universal, a principal disputa numa democracia moderna consistiria na restrição ou ampliação dos elegíveis (não dos eleitores). Esse seria o campo de batalhas crucial da democracia na atualidade, inclusive da brasileira.

É segundo esse marco teórico que Santos se posiciona no debate sobre reforma política: quanto maiores as competições eleitoral e partidária, mais democrático é um sistema político, ao passo que, quanto menores 
elas forem, mais oligárquico. Do mesmo modo, o autor avalia o processo de democratização da sociedade brasileira, valorizando-o, evidenciado por diferentes fatores: pelo processo de consolidação da justiça eleitoral (tornando os pleitos cada vez mais idôneos), pela legalização de partidos antes proibidos no país, pelo crescimento e nacionalização dessas instituições, pela veloz expansão do eleitorado nacional (sendo ela mais acentuada nas regiões antes marginalizadas da competição política - Norte e Centro-Oeste), pela elevação do número médio de candidatos aos cargos eletivos e, por fim, por um oscilante, mas satisfatório índice de renovação parlamentar. Desde os anos 1930 até os dias de hoje (e, particularmente, radicalizado nas últimas duas décadas), o Brasil estaria vivendo um processo de expansão cívica: "o extraordinário movimento cívico de transformação da população em cidadãoseleitores aparece e impressiona" (Santos, 2007b:56). Falando literalmente de uma "alvorada" (idem, 1998b:192) democrática brasileira, o autor, em sua apologia das atuais instituições políticas do país, conclui: "está evidenciada a fundamental transformação do sistema eleitoral-partidário brasileiro, que passou de oligárquico a poliárquico" (Santos, 2007b:57). Crescendo a imprevisibilidade da competição política no Brasil, e tendo o eleitorado aproveitado razoavelmente as oportunidades de oxigenar a vida política do país, os neo-oligarcas teriam, consequentemente, iniciado um processo de reação, sobretudo, por meio da proposição de alterações nas "regras do jogo político" - a reforma eleitoral.

\section{AS PROPOSTAS DE REFORMA: COMPETIÇÃO POLÍTICA E RESISTÊNCIA OLIGÁRQUICA}

Mas quais seriam as principais propostas dos neo-oligarcas? Três delas serão avaliadas aqui, as mais comentadas por Wanderley Guilherme: 0 sistema eleitoral de representação majoritária, a redução no número de partidos políticos e a adoção do voto em lista fechada. Em seguida, falar-se-á a respeito da maior utilização de instrumentos de participação direta, reivindicação alardeada por outro "grupo", mas também prejudicial à democracia brasileira, na perspectiva de Santos.

Quanto ao sistema eleitoral de representação proporcional, o autor observa e alerta que a ofensiva oligárquica se dirige preferencialmente para a Câmara dos Deputados, pois é nela que a competitividade é maior. Conspirando contra os princípios assegurados na Constituição de 1988, haveria uma tentativa de convencer, por cinco razões princi- 
pais, a opinião pública brasileira dos supostos males do sistema proporcional.

Em primeiro lugar, argumenta-se a favor da maior representatividade do sistema eleitoral majoritário. Falso, replica Santos, pois esse sistema, chamado normalmente de voto distrital, desperdiça os votos dos eleitores que não formaram a maioria, excluindo as minorias e concentrando o poder nas mãos das maiorias. No livro Dois Escritos Democráticos de José de Alencar, publicado em 1991, Wanderley Guilherme dos Santos recupera os argumentos desse pensador brasileiro para contra-argumentar precisamente as críticas feitas à representação proporcional ${ }^{8}$. Santos resume: "sistemas eleitorais não filtram caráter ou competência parlamentar, apenas traduzem a capacidade diferencial dos candidatos em acumular votos" (2007b:79).

Uma segunda crítica apresentada ao sistema proporcional é que ele produziria um eleitorado mais fragmentado. Santos observa que há uma inversão de causalidade: na realidade, não é que o eleitorado se fragmente por causa do sistema proporcional, mas que o sistema proporcional se mostra fragmentado quando o eleitorado é igualmente dividido. Precisamente por isso, esse sistema se justifica mais do que o distrital: um eleitorado diversificado demanda um sistema eleitoral capaz de representar proporcionalmente todos os estratos sociais.

Uma terceira justificativa apresentada é que existiria uma tendência mundial em substituir o sistema proporcional pelo majoritário, sendo o primeiro um anacronismo. Santos esclarece que, se há alguma tendência nas democracias modernas, é precisamente a contrária: "todos os países de representação proporcional optaram por ele após longa experiência com o sistema majoritário, este sim o mais antigo, o do atraso" (Santos, 1994:7).

Um quarto motivo elencado pelos defensores dessa reforma política é que o sistema distrital diminuiria os custos da campanha eleitoral, elevados nas democracias hodiernas. Santos ironiza, afirmando que toda competição democrática é cara, quer pela "abundância de competidores" (caso dos sistemas proporcionais), quer pela "escassez de postos" (caso dos sistemas majoritários) (1994:7).

Um último, mas não menos importante, fator que justificaria a substituição do voto proporcional pelo distrital seria a sua maior estabilidade. O autor contesta semelhante associação, esclarecendo que "estabi- 
lidade política é tema controverso e jamais foi demonstrado que seja consequência de qualquer uma das instituições políticas: sistemas ou formas de governo, regimes, códigos eleitorais ou partidários" (Santos, 1994:6). Contra a previsão incerta que associa estabilidade a certos arranjos institucionais, Wanderley Guilherme atesta que o que se sabe é que sistemas majoritários "violentam os princípios de justiça alocativa e distributiva e cristalizam oligarquias partidário-parlamentares" (idem, ibidem).

Outra proposta da reforma política relacionada à estabilidade é o número de partidos. A cláusula de barreira, por exemplo, visa impedir a proliferação de partidos que serviriam como "legendas de aluguel". Um número elevado de partidos, a princípio, dificultaria a escolha do eleitor e, pior, tornaria o país "ingovernável", dado que o Executivo teria que lidar com uma base aliada excessivamente heterogênea. Multipartidarismo estaria associado com frequência à fragmentação partidária e essa, por seu turno, à ingovernabilidade. Contra essa interpretação, Santos afirma que fragmentação político-partidária não é o resultado do número elevado ou reduzido de siglas partidárias, mas da distribuição das cadeiras no Parlamento entre os partidos. Em outras palavras: elevado número de legendas partidárias não implica necessariamente numeroso conjunto de partidos parlamentarmente efetivos. Mesmo um sistema bipartidário pode atingir um índice elevado de fragmentação se cada um dos partidos obtiver $50 \%$ dos postos em disputa, assim como o multipartidarismo pode resultar em um Parlamento pouco fragmentado. Mais importante que isso, o argumento é pérfido porque fragmentação não é causa suficiente da ingovernabilidade. Ele argumenta que países cronicamente instáveis, como a Itália, possuem índices de fragmentação menores do que os países escandinavos, conhecidos por serem secularmente estáveis. O Brasil, por exemplo, possui índice menor do que esses países. A África do Sul possui reduzida fragmentação partidária, sendo sabidamente menos democrática do que os exemplos citados. Em resumo, não há nenhuma correlação comprovada entre sistema eleitoral e fragmentação partidária e, muito menos, entre essa e instabilidade.

Outro argumento apresentado por Santos contra qualquer medida que venha a limitar o número de partidos (além de que qualquer critério seria sempre arbitrário, como o dos $5 \%$ de votos nacionais) é que mesmo partidos que possuem no limite apenas um único representante no 
Parlamento são tão legítimos quanto um representante de um partido majoritário.

Cada representante de um partido de cem deputados é curador da mesmíssima legitimidade implícita no mandato do representante solitário. Os outros noventa e nove membros do partido não lhe acrescentam nada em dignidade, embora sejam utilíssimos em falcatruas. Não há, pois, fundamento para impedir que alguém, eleito, exerça o mandato, ou para que seja obrigado a mudar de partido (estelionato eleitoral) porque sua agremiação não alcançou um número cabalístico inventado pelos oligarcas. Um deputado equivale a um sobre quinhentos e três avos de poder parlamentar; não produz instabilidade alguma. Mas corresponde a cem por cento da representação de quem nele votou. Cassá-lo equivale a induzir seus eleitores a buscarem canais alternativos à vida institucional para manifestar insatisfação ou registrar demandas. (Santos, 1994:16)

Nesse debate há também a putativa associação entre o elevado número de candidatos e uma maior dificuldade de escolha por parte do eleitor. Sobre isso, ele rebate: um maior número de candidatos significa obviamente uma competição mais acirrada pelos cargos de poder, o que, por dedução, implica uma valorização do voto de cada eleitor. Uma oligarquia política produz as consequências similares às de um oligopólio econômico: restringe a liberdade de escolha do eleitor, pela redução na oferta de candidatos, e aumenta o custo de seus serviços ("a taxa de impunidade se eleva e os políticos ficam mais livres para impor suas preferências específicas" - Santos, 1994:169-170). Os pequenos partidos, por si só, não são fonte de problemas; ao contrário, eles desempenham um importante papel, aproximando-se dos eleitores mais afastados das grandes capitais ${ }^{9}$.

Uma terceira proposta de reforma política criticada por Wanderley Guilherme consiste na adoção do voto em lista fechada, medida supostamente capaz de fortalecer os partidos políticos. Recuperando mais uma vez a contribuição de Michels, o autor assevera que tal proposta produzirá uma oligarquização dos processos de indicação dos candidatos aos cargos eletivos. "É transparente, nesse caso, a michelliana oligarquização da política por via partidária, particularmente quando, por conta do requisito da filiação, transfere-se à máquina burocrático-partidária o poder de ordenar, em sistema de listas fechadas, os candidatos preferenciais do partido" (Santos, 2007b:42). 
Não caberia mais ao eleitor escolher quem particularmente merece o seu voto, mas às cúpulas partidárias (não eleitas e tendencialmente centralizadoras). Ele se pergunta: “com o voto por legenda haverá espaço para os candidatos dos movimentos negros, dos movimentos feministas, dos movimentos dos homossexuais, dos movimentos dos marginalizados da vida?" (Santos, 2005:4).

A última proposta de reforma a ser avaliada aqui é a adoção e/ou maior utilização de novos mecanismos de participação direta, como o plebiscito, por exemplo. Essa seria a reivindicação dos neorrepublicanos (ou dos teóricos da democracia participativa). Para Santos, eles não são idênticos aos "neo-oligarcas", mas, de qualquer modo, compartilhariam com eles um diagnóstico negativo da democracia brasileira, ainda que por razões distintas. A retórica neorrepublicana, alicerçada nos modelos de política da Antiguidade, identifica na permanência das desigualdades sociais e nas, supostas, apatia cívica e descrença nas instituições políticas, sintomas da crise na democracia brasileira, fenômeno esse também verificado em outros países desenvolvidos. Seria necessário recorrer mais sistematicamente à participação direta, a fim de vencer esse distanciamento entre o cidadão comum e a vida pública.

O diagnóstico do neorrepublicanismo brasileiro apoia-se na avaliação que a opinião pública costuma fazer sobre as instituições do país, particularmente as instituições políticas. Segundo a crítica, a avaliação das instituições evidenciaria uma deficiência real antes que conjuntural viés negativo em relação aos acontecimentos. Não compartilho da avaliação que os neorrepublicanos propõem sobre as instituições políticas, mas, para efeito de argumentação, concedo a possibilidade de que exista um déficit democrático no país. Ainda assim, sustento que a terapia proposta - a democracia direta -, ademais de imprecisamente formulada, evita questões essenciais na instituição de uma cidade democrática. (Santos, 2007a:40, ênfases do autor)

Ele acusa esse discurso de se constituir numa "importação de um produto deteriorado na travessia" (Santos, 2007a:26), ou seja, a incorporação de um conjunto de problemáticas formuladas nos países de democracia mais decantada, que, se já não constituem diagnósticos duvidosos sobre esses países, não fazem nenhum sentido no caso brasileiro, haja vista o mencionado processo de expansão cívica. Mais uma vez, o tema da imitação dos intelectuais brasileiros em relação a ideias "estrangeiras" reaparece na obra desse autor brasileiro (que, como vimos, 
concordara com a crítica de Oliveira Vianna aos "idealistas utópicos"), agora contra aqueles que atestam um déficit de participação no país.

Em relação à ideia de que a democracia brasileira vai mal, haja vista a permanência das desigualdades sociais ao longo dos anos (elemento corrente do discurso neorrepublicano), o autor reconhece que a estabilidade das desigualdades, depois da conversão do país de uma oligarquia em uma poliarquia, é de difícil explicação. No entanto, ele declara explicitamente que a finalidade da democracia não é, necessariamente, diminuir as desigualdades sociais entre os cidadãos, mas tão somente as desigualdades políticas e jurídicas (Santos, 2007a:145). Não se deve, alerta ele, avaliar as instituições políticas e o seu desenvolvimento no século XX em função da permanência das assimetrias sociais entre os indivíduos.

Quanto à suposta "terapêutica" neorrepublicana, baseada na ideia de que "a qualidade do governo depende da permanente mobilização" (Santos, 2007a:29), o autor critica o expediente dos plebiscitos, na medida em que eles não permitem o confronto argumentativo (como ocorre nos tradicionais parlamentos de tamanho médio) e, ademais, não permitem a revisão de suas decisões. Por conta dessas razões, esses mecanismos deveriam ser utilizados de modo moderado, nunca a substituir o funcionamento normal dos parlamentos. Contra o pressuposto neorrepublicano sobre a mobilização e que implica uma concepção de "bem comum" (como uma moralidade comum), Wanderley Guilherme argumenta que uma democracia pode conviver com doses moderadas de apatia e egoísmo político (Santos, 2007a:77-78). O autor associa a retomada do republicanismo ao "autocratismo", um desejo indisfarçado de querer impor a todos as mesmas preferências, colocando em risco a liberdade individual: "Os profetas da participação integral, hoje, são os potenciais sequestradores da liberdade de amanhã. Às vezes em nome de um ontem, tal o ontem grego, que, em verdade, é obscuro e polêmico" (Santos, 2007a:48).

\section{A QUALIDADE DA DEMOCRACIA BRASILEIRA EM DISPUTA}

Identificando-se como um "cético moderado", Santos, além de contestar veementemente a "ofensiva neo-oligárquica" e a crítica neorrepublicana à democracia brasileira, recomenda cautela diante de qualquer inovação institucional: seus resultados, em geral, destoam das expectativas de seus defensores e podem significar retrocessos políticos. $\mathrm{Na}$ 
origem das democracias, não apenas entre os conservadores, mas entre todos os "grandes engenheiros institucionais" (Santos, 1998b:144), vigorou sempre a inteligente estratégia da moderação, quando o assunto é transformar as normas fundamentais do sistema político. Isso porque, sendo a ordem social imprevisível, não é possível desenvolver um sistema fechado de explicações sobre ela. Soma-se à sua postura epistemológica cética a sua convicção quanto à precocidade da democracia uma experiência institucional, nos seus termos, "recentíssima" (Santos, 2007a:156). A democracia é uma novidade e, enquanto tal, as condições necessárias para o seu bom funcionamento são apenas conhecidas parcialmente.

Embora declare não ser um advogado do "imobilismo" ou da "mumificação institucional" (Santos, 1994:21), são poucas as passagens em sua obra em que ele admite a plausibilidade de algum tipo de reforma política para o Brasil $^{10}$. Sob a suposta ameaça a rondar a democracia brasileira, Wanderley Guilherme reafirma seu compromisso: "os neo-oligarcas optaram pelos atentados institucionais. Por mim, voto pela boa competição política. Esta é a minha apologia democrática" (Santos, 1998b:192). Contra aqueles que, na sua visão, idealizam uma democracia melhor, marcada pela intensa participação política do cidadão comum (como os neorrepublicanos), afirma: "tenho uma preferência clara: sou, em primeiro lugar, favorável à democracia; subsidiariamente, aceito discutir os méritos efetivos de quaisquer novos instrumentos de participação política" (2007a:10).

Sobre o suposto descontentamento difuso em relação às democracias (a ideia de que as democracias hoje carecem de confiança), Santos assegura que o regime democrático implica certa "anomalia", na medida em que considera como, a princípio, justas quaisquer reivindicações, mesmo aquelas que colocam em risco a própria sobrevivência do regime. Nesse sentido, o fenômeno dos "irredentos", isto é, a existência de certas moções em relação às quais a "democracia não pode atender" (2007a:157), é inerente à vida democrática. Ao contrário de outros tipos de regimes políticos que tendem a calar as vozes descontentes, na poliarquia elas encontram guarida pela própria natureza de suas instituições.

Para encerrar, cumpre avaliar mais criticamente as ideias desse autor, a fim de pensar a sua contribuição no entendimento da formação da democracia brasileira. Sobre isso, vale destacar o papel fundamental 
desempenhado por ele junto a outros intelectuais brasileiros, na institucionalização da Ciência Política no país, na segunda metade do século $X X^{11}$. Mais do que isso: pode-se tomá-lo como um expoente de uma tradição que se estabelece no Brasil a essa época e que ainda é frequentemente consultada (por exemplo, quando se discute a reforma política hoje), que consiste na análise da política brasileira, sobretudo de suas instituições, como os partidos, o Poder Legislativo etc. Ainda sob esse prisma, destaca-se também sua contribuição na formulação de novos indicadores da política institucional, tendo eles sido incorporados pelo mainstream dos estudos eleitorais ${ }^{12}$.

Mas não é correto caracterizar sua obra como precípua ou exclusivamente institucionalista. Se, em alguns de seus textos há uma ênfase na dimensão institucional (como em Sessenta e Quatro), noutros títulos (como em Razões da Desordem), o autor avalia a cultura política brasileira, ponderando, como se viu, que a poliarquia brasileira não se consolidou totalmente (ainda que esteja em momento de franca expansão) precisamente porque não conseguiu romper com a sociabilidade hobbesiana infensa às instituições formais da política. O que o país precisa ainda, diz ele, é de uma cultura cívica efetiva.

No entanto, fica a indagação de por que, tendo satisfeito os requisitos de uma poliarquia, tal cultura não se formou (e o que fazer para transformar essa situação). Quer dizer, se a obra de Santos é bastante rica para se compreender o Brasil (na medida em que, por exemplo, permite considerar a formação de uma ordem democrática segundo um processo histórico complexo e passível de retrocesso), ela, todavia, não apresenta uma resposta clara de como se superar o impasse do "híbrido institucional" brasileiro. A proposta de "constitucionalização" do território nacional, sugerida por Santos, não parece ser capaz de solucionar totalmente o problema, pois se é verdade que muitos cidadãos no país carecem ainda dos direitos constitucionais mais básicos, é verdade também que o enfrentamento desse cenário pressupõe igualmente garantir as "bases materiais" para o exercício desses direitos. Assim, embora se compreendam as razões pelas quais Wanderley Guilherme dos Santos rechaça a avaliação negativa da democracia brasileira face à manutenção das desigualdades sociais (num contexto de defesas arrebatadas de inovação institucional, embora nem sempre claras e adequadas, feitas, por exemplo, por parte da intelectualidade e da mídia brasileira), a solução desse autor em dissociar a democracia da igualdade material é, no mínimo, problemática, na medida em que essa últi- 
ma constitui um patamar sine qua non para o pleno exercício dos direitos políticos.

(Recebido para publicação em dezembro de 2013)

(Reapresentado em fevereiro de 2014)

(Aprovado para publicação em fevereiro de 2014)

\section{NOTAS}

1. Sobre isso ver, por exemplo, Sorj (2001).

2. Em texto mais recente, escrito com Amaury de Souza, Lamounier, baseado em entrevistas com "104 cientistas políticos e juízes" (Souza e Lamounier, 2006:44), assevera que se firmou no país certo consenso quanto à necessidade imperiosa da reforma política. Novamente emerge o tema do multipartidarismo e da sua inevitável e suposta consequência, a fragmentação partidária, causa, por seu turno, da ingovernabilidade crônica brasileira (embora a proposta parlamentarista, defendida tão arraigadamente uma década atrás, tenha sido deixada de lado agora). Profilaticamente, os autores recomendam a adoção da cláusula de barreiras de 5\% dos votos nacionais (como requisito sem o qual um partido não estaria qualificado para a representação parlamentar), a adoção de um sistema eleitoral misto "que combinasse disputas majoritárias em distritos uninominais com eleições proporcionais de lista fechada nas circunscrições estaduais" (ibidem:56), além da criação de dispositivos específicos para garantir a disciplina partidária, indo, assim, ao encontro de alguns projetos em discussão atualmente no Congresso, pelo menos, em suas diretrizes gerais.

3. Sobre isso, ver Moreira (2008).

4. São elas: 1) liberdade de formar e aderir a organizações; 2) liberdade de expressão;3) direito de voto; 4) elegibilidade para cargos públicos; 5) direito de líderes políticos disputarem apoio (5a: direito de líderes políticos disputarem votos); 6) fontes alternativas de informação; 7) eleições livres e idôneas; 8) instituições para fazer com que as políticas governamentais dependam de eleições e de outras manifestações de preferência (Dahl, 2005:27).

5. Nesse passo da argumentação, Santos retoma os escritos de Oliveira Vianna, subscrevendo, em linhas gerais, seu diagnóstico sobre o país, do período colonial à Primeira República. Voltar-se-á a esse ponto adiante.

6. Deve-se lembrar que várias das propostas de reforma política no Brasil são justificadas como medidas necessárias para combater a fragilidade partidária, como a cláusula de barreiras, o voto em lista fechada e a perda de mandato para parlamentares que troquem de partidos.

7. Nesse diapasão, é preciso recordar os avanços obtidos com a reforma eleitoral promovida pelo Código de 1932 que, além de garantir maior lisura aos pleitos eleitorais (com a adoção do voto secreto e a criação da Justiça Eleitoral), garantiu a extensão do sufrágio às mulheres brasileiras.

8. Santos encontra no texto alencariano vários temas que constituem a marca de seu próprio pensamento: a defesa da democracia como regime que mais expressa as clivagens de opinião da sociedade; a defesa do sistema representativo proporcional 
como uma forma de representação política mais justa do que o sistema majoritário; a defesa da ampliação da participação política, por meio do direito do voto, como condição para realização dos outros direitos; a defesa do sistema partidário, como forma de condensação da soberania civil, bem como a defesa da alternância partidária no poder.

9. É interessante notar que os temas da estabilidade política, da fragmentação partidária e do sistema eleitoral proporcional acompanham a obra desse autor já há algumas décadas. Em sua tese de doutorado, Sessenta e Quatro: Anatomia da Crise, Wanderley Guilherme já polemizava com a literatura da Ciência Política a respeito dessa temática. Santos assevera que o número de partidos não tem qualquer relevância para a solução de conflitos políticos. A fragmentação parlamentar (que não se confunde com o número de partidos) só gera instabilidade quando associada ao processo de radicalização ideológica. Sistemas fragmentados, mas não radicalizados, criam uma situação na qual a negociação com os diversos partidos efetivos torna-se parte do dia a dia do governo. Somente nos casos de radicalização e de fragmentação (como no cenário político brasileiro do pré-64) tem-se uma conjuntura em que nem o Executivo consegue aprovar as medidas necessárias para governar, nem o Legislativo consegue formar maioria para aprovar outra agenda política. Trata-se do que ele convencionou chamar "crise de paralisia decisória".

10. Em entrevista a Juarez Guimarães, o autor reconhece que há problemas no modelo brasileiro de financiamento de campanhas eleitorais no Brasil, particularmente sobre a doação a candidatos feita pelo setor financeiro (e sugere que bancos sejam proibidos de doar dinheiro para políticos), mas não crê na solução desses problemas por meio da adoção do sistema exclusivamente público (Santos, 2006:117). Noutro depoimento, a Maysa Provedello, Santos reconhece que a infidelidade partidária é um problema no Brasil, mas apenas afirma vagamente que "isso pode ser resolvido com mudanças na legislação eleitoral" (Santos, 2005:4).

11. Esse argumento foi mais extensamente desenvolvido em Moreira (2008).

12. O índice de competitividade (número médio de candidatos por vagas em disputa em eleições), inventado por Santos, acabou sendo adotado pelas estatísticas do TSE (Tribunal Superior Eleitoral). Além dele, dois outros indicadores criados por ele (renovação parlamentar e estabilidade governamental) consagraram-se como importantes no estudo da política (Santos, 2005:5). 


\section{REFERÊNCIAS BIBLIOGRÁFICAS}

DAHL, Robert. (1989), Democracy and Its Critics. New Haven, Yale University Press. . (2005), Poliarquia: Participação e Oposição. São Paulo, Edusp.

LAMOUNIER, Bolívar. (1992), “O Modelo Institucional dos Anos 30 e a Presente Crise Brasileira". Estudos Avançados, vol. 6, no 14, pp. 39-57.

MOREIRA, Marcelo S. (2008), O Diálogo Crítico com a Teoria Poliárquica no Pensamento Político de Wanderley Guilherme dos Santos. Dissertação de Mestrado em Ciência Política, Faculdade de Filosofia e Ciências Humanas, Universidade Federal de Minas Gerais, Belo Horizonte.

SANTOS, Wanderley Guilherme dos. (1970), "Raízes da Imaginação Política Brasileira". DADOS - Revista de Ciências Sociais, no 7, pp. 137-161.

. (1978), Ordem Burguesa e Liberalismo Político. São Paulo, Duas Cidades.

. (1979), Cidadania e Justiça: A Política Social na Ordem Brasileira. Rio de Janeiro, Campus.

. (1986), Sessenta e Quatro: Anatomia da Crise. São Paulo, Vértice.

. (1991), Dois Escritos Democráticos de Joséde Alencar: Sistema Representativo, 1868; Reforma Eleitoral, 1874. Rio de Janeiro, Ed. UFRJ.

__. (1993), Razões da Desordem. Rio de Janeiro, Rocco.

(1994), Regresso: Máscaras Institucionais do Liberalismo Oligárquico. Rio de Janeiro, Opera Nostra.

. (1998a), "Poliarquia em 3D". DADOS - Revista de Ciências Sociais, vol. 41, no 2, pp. 207-281.

. (1998b), Décadas de Espanto e uma Apologia Democrática. Rio de Janeiro, Rocco.

. (2005), “A Democracia ainda é Jovem”. Desafios do Desenvolvimento, ano 2, vol. 12. Brasília, Ipea.

. (2006), "O Grande Jogo Impugnativo: Entrevista com Wanderley Guilherme dos Santos", in M. Chauí et al. Leituras da Crise: Diálogos sobre o PT, a Democracia Brasileira e o Socialismo. São Paulo, Ed. Fundação Perseu Abramo, pp. 85-140.

(2007a), O Paradoxo de Rousseau: Uma Interpretação Democrática da Vontade Geral. Rio de Janeiro, Rocco.

. (2007b), Governabilidade e Democracia Natural. Rio de Janeiro, FGV Editora.

SORJ, Bernardo. (2001), A Construção Intelectual do Brasil Contemporâneo: Da Resistência à Ditadura ao Governo FHC. Rio de Janeiro, J. Zahar.

SOUZA, Amaury de e LAMOUNIER, Bolívar. (2006), “O Futuro da Democracia: Cenários Político-institucionais até 2022". Estudos Avançados, vol. 20, no 56, pp. 43-60.

DADOS - Revista de Ciências Sociais, Rio de Janeiro, vol. 57, n², 2014 
RESUMO

A Poliarquia Brasileira e a Reforma Política: Análise de uma Contribuição de Wanderley Guilherme dos Santos à Teoria Politica

O artigo avalia a contribuição de Wanderley Guilherme dos Santos para a teoria política, com especial atenção para o caso da democratização do Brasil. Sem pretensão de apresentar uma análise ampla de todos os aspectos da obra desse autor, o trabalho a recupera a partir de suas polêmicas em torno da reforma política. A interpretação de Santos sobre os regimes políticos, formulada criticamente à luz da teoria da poliarquia, leva-o a contestar aqueles que asseveram a má qualidade da democracia do país, atestando, ao contrário, o seu substantivo desenvolvimento nas últimas décadas. Formada também em contato com algumas correntes do pensamento político brasileiro, anteriores à institucionalização das ciências sociais, a obra de Santos, um dos pais-fundadores da moderna ciência política no país, é importante para se compreender os avanços e os impasses da democracia, e os riscos de muitas das propostas de reforma política em pauta.

Palavras-chave: Wanderley Guilherme dos Santos; poliarquia; reforma política; teoria política; pensamento político brasileiro

\begin{abstract}
Brazilian Polyarchy and Political Reform: Analysis of a Contribution to Political Theory by Wanderley Guilherme dos Santos

This article evaluates the contribution made by Wanderley Guilherme dos Santos to political theory, specifically with regard to the case of democratization in Brazil. It focuses on a selected aspect of this author's work, namely the polemic concerning political reform. Dos Santos's interpretation of political regimes, critically formulated in light of the theory of polyarchy, is determinant in his challenge to those who asserted the low quality of Brazilian democracy, and underlines the substantial progress achieved during the last decades. Building upon strands of Brazilian political thought that precede the institutionalization of social sciences, the work of dos Santos, one of the founding fathers of modern political science in Brazil, is important in the attempt to understand the advances and impasses of democracy, as well as the risks of the many proposals for political reform in the agenda.
\end{abstract}

Keywords: Wanderley Guilherme dos Santos; polyarchy; political reform; political theory; Brazilian political thought 


\section{RÉSUMÉ}

La Polyarchie Brésilienne et la Réforme Politique: Analyse de l'Apport de Wanderley Guilherme dos Santos à la Théorie Politique

Dans cet article, on examine la contribution de Wanderley Guilherme dos Santos à la théorie politique en s'attachant à la démocratisation au Brésil. Il ne s'agit pas d'une analyse de tous les aspects des travaux de cet auteur, mais de ses évaluations de la réforme politique. L'interprétation critique de Santos sur les régimes politiques, présentée à la lumière de la théorie de la polyarchie le mène à contester ceux qui soutiennent l'existence $d^{\prime}$ une mauvaise qualité de démocratie au Brésil, en montrant, au contraire, son réel développement au cours des dernières décennies. Construite selon certains courants de la pensée politique brésilienne précédant l'institutionnalisation des sciences sociales, $l^{\prime} œ u v r e$ de Santos, l'un des fondateurs des sciences politiques modernes au Brésil, est très importante pour que nous comprenions les progrès et les impasses de la démocratie, ainsi que les risques de certaines propositions de réformes politiques en cours.

Mots-clés: Wanderley Guilherme dos Santos; polyarchie; réforme politique; théorie politique; pensée politique brésilienne

\section{RESUMEN}

La Poliarquía Brasileña y la Reforma Política: Un Análisis de la Contribución de Wanderley Guilherme dos Santos a la Teoría Política

El artículo evalúa la contribución de Wanderley Guilherme dos Santos a la teoría política, centrándose en el caso de la democratización de Brasil. El trabajo recupera la obra de este autor a partir de sus polémicas en torno a la reforma política, sin pretender realizar un análisis amplio de todos sus aspectos. A la luz de la teoría de la poliarquía, Santos interpreta críticamente los regímenes políticos, y, en respuesta a aquellos que aseveran la mala calidad de la democracia en Brasil, da testimonio del desarrollo sustancial que éstos han experimentado en las últimas décadas. Formada también en contacto con algunas corrientes del pensamiento político brasileño previas a la institucionalización de las ciencias sociales, la obra de Santos, uno de los padres fundadores de la ciencia política del país, resulta fundamental para comprender los avances y crisis de la democracia y los riesgos de muchas de las propuestas de reforma política en discusión.

Palabras clave: Wanderley Guilherme dos Santos; poliarquía; reforma política; teoría política; pensamiento político brasileño 